\title{
9
}

\section{LAS CLÁUSULAS DE SOSTENIBILIDAD MEDIOAMBIENTAL EN LOS ACUERDOS COMERCIALES DE LA UE}

Las cláusulas de sostenibilidad medioambiental se han convertido en una constante en los acuerdos comerciales de la Unión Europea. Son el resultado de la regionalización en la gobernanza medioambiental y en la comercial. Las cláusulas medioambientales pueden clasificarse en distintas categorías, en función del objetivo perseguido y de su grado de concreción. Estas provisiones son solo un caso concreto de la creciente interrelación entre la política comercial y el medioambiente. El presente artículo, tras revisar el concepto de sostenibilidad ambiental y estudiar las formas en que las relaciones comerciales afectan al medioambiente, realiza una descripción de las cláusulas medioambientales para los acuerdos en los que la UE es una de las partes, comparándolas con las cláusulas medioambientales incluidas en los acuerdos comerciales en los que EE. UU. y China son parte, con el objetivo de sentar las bases para futuros estudios en los que se evalúe la incidencia de dichas cláusulas sobre el desarrollo sostenible de los socios comerciales de la UE.

Palabras clave: cláusula de sostenibilidad medioambiental, acuerdo comercial, UE, evaluación, indicador.

Clasificación JEL: F13, K32, Q28.

\section{Introducción}

Las últimas décadas han dado lugar a importantes cambios en las preferencias sociales globales $y$, en consecuencia, a la necesidad de reconfiguración de determinadas políticas económicas. Por un lado, ha aumentado la preocupación por cuestiones medioambientales. Por otro, los efectos del proceso globalizador, el desarrollo

\footnotetext{
* Técnico Comercial y Economista del Estado.

Versión de agosto de 2021.

DOI: https://doi.org/10.32796/bice.2021.3138.7276
}

de las cadenas globales de valor, la transición digital o la preocupación por el medioambiente han abierto debates sobre la necesidad de reconfigurar la política comercial ${ }^{1}$.

Con estas tendencias como base, el presente artículo se centra en determinados puntos en común entre la política comercial y la sostenibilidad medioambiental. Concretamente, se realiza una primera aproximación a cómo la inclusión de cláusulas de sostenibilidad $\triangleright$

Véase, por ejemplo, la Trade Policy Review de la Unión Europea, buscando «An Open, Sustainable and Assertive Trade Policy». 
medioambiental en los acuerdos comerciales de la UE puede incidir sobre el desarrollo sostenible de sus socios comerciales. Todo ello con la perspectiva de que la UE cuenta con potenciales instrumentos de política comercial alternativos, como las denominadas tasas al carbono, para incidir sobre el medioambiente.

Se trata de una línea de investigación incipiente, con distintos grados de desarrollo en función de la problemática concreta considerada, pero con una clara tendencia creciente. Siendo así, resulta interesante plantear una serie de aclaraciones que servirán para acotar el problema tratado y comunicar adecuadamente el objetivo del artículo.

En primer lugar, el concepto de sostenibilidad presenta una naturaleza multidimensional. El consenso generalizado acepta que la sostenibilidad se vertebra en torno a tres pilares: económico, medioambiental y social. Sin ir más lejos, esta es la concepción acuñada por los Objetivos de Desarrollo Sostenible (ODS) de Naciones Unidas (NN. UU.) y, en consecuencia, por distintas instituciones en sus políticas y recomendaciones, como la Unión Europea (UE) o la Organización para la Cooperación y Desarrollo Económicos (OCDE). Como se explicará posteriormente, el presente artículo se centrará en el pilar medioambiental, que está siendo objeto de una creciente atención por parte de la teoría económica y para el que se está mejorando progresivamente el acceso a datos.

En segundo lugar, la UE cuenta con distintos instrumentos de política comercial que pueden tener incidencia sobre el factor de sostenibilidad de sus socios comerciales. Es fundamental distinguir entre los efectos que la liberalización comercial (firma de acuerdos comerciales per se) tiene sobre la sostenibilidad y los instrumentos de política comercial concretos que pueden ser usados para impulsar el desarrollo sostenible (determinadas medidas comerciales o cláusulas de sostenibilidad en los propios acuerdos comerciales).

La UE, como principal actor comercial a nivel global, cuenta con distintos instrumentos de política comercial que pueden afectar al medioambiente, los cuales se basan en fomentar la cooperación con sus socios comerciales, recompensarles («zanahoria») o introducir sanciones («palo»). En la práctica, el auge de los acuerdos regionales muestra cómo el instrumento de política comercial paradigmático en este ámbito son las cláusulas de sostenibilidad. Desde hace décadas, la UE utiliza estas cláusulas, principalmente en los ámbitos medioambiental, social y, en los últimos años, de igualdad de género².

Ahora bien, existen distintos tipos de cláusulas de sostenibilidad medioambiental. Las cláusulas se pueden diferenciar en base a distintos criterios. Los objetivos medioambientales pretendidos o el grado de concreción con el que están diseñadas las cláusulas son los criterios principales. La forma en la que estos criterios se plasmen en cada acuerdo en concreto dependerá de la estructura económica de los socios comerciales de la UE. Merece la pena detenerse en el grado de concreción de las cláusulas, pudiendo distinguir cláusulas generalistas, plasmadas como simples declaraciones de intenciones, y, en el extremo opuesto, cláusulas detalladas y con objetivos explícitos.

Finalmente, otro factor determinante en esta diferenciación es si el acuerdo contempla un sistema de supervisión y control del cumplimiento de las cláusulas (enforcement) o la obligación de realizar evaluaciones periódicas del impacto que están teniendo, con vistas a $\triangleright$

Gender equality in EU trade agreements, European Parliament resolution of 13 March 2018 on gender equality in EU trade agreements (2017/2015[INI]). 
mejorar su diseño. Es relevante comentar la existencia de informes anuales de seguimiento sobre la implementación de los acuerdos comerciales de la UE, los cuales incluyen un capítulo dedicado a la sostenibilidad medioambiental (Comisión Europea, 2020).

De esta forma, el objetivo del presente artículo es plantear una primera aproximación a la interrelación entre las cláusulas de sostenibilidad de los acuerdos comerciales de la UE y su efecto sobre el desarrollo sostenible de sus socios comerciales. Este objetivo se hará con la perspectiva en todo momento de que la política comercial de la UE puede afectar a la sostenibilidad medioambiental de sus socios comerciales por otras vías.

Para ello se analizará, desde una perspectiva teórica, el concepto de sostenibilidad y cómo la política comercial puede tener incidencia sobre ella. Todo ello con vistas a sentar las bases para poder realizar en futuros trabajos una estimación de los efectos de las cláusulas medioambientales y abordar los principales problemas que pueden surgir en la misma.

\section{Sostenibilidad}

\subsection{Explicación teórica de la sostenibilidad}

El consenso generalizado defiende que los problemas de sostenibilidad medioambiental presentan costes y beneficios presentes y futuros. Estos costes y beneficios se distribuyen de forma asimétrica, dando lugar a problemas de desigualdad que se reflejan en la preocupación actual por que el crecimiento sea no solo «sostenible», sino también «inclusivo». Por tanto, la búsqueda de la sostenibilidad medioambiental plantea la necesidad de adoptar un enfoque intertemporal y un tratamiento desagregado de la información disponible, con vistas a abordar los retos de política económica asociados a dicha reasignación sectorial de recursos.

En un determinado momento del tiempo, shocks con efectos de carácter permanente y de gran intensidad pueden tener efectos asimétricos entre distintos agentes económicos y entre regiones. Así surgen preocupaciones por la desigualdad entre colectivos y regiones ${ }^{3}$. Es necesario realizar un tratamiento desagregado de las previsiones y los resultados (por colectivos y regiones) para efectuar un análisis completo y riguroso de los efectos asociados a cambios relevantes en la estructura económica.

Intertemporalmente, aparecen costes y beneficios que, previsiblemente, se distribuirán de forma desigual e incierta a lo largo del tiempo y, también, entre agentes y regiones. Un caso particular de distribución desigual a lo largo del tiempo de los costes y beneficios es la conocida como «tragedia del horizonte» (Carney, 29 de septiembre de 2015). Es un caso de especial interés el ámbito medioambiental. Consiste en que los efectos del cambio climático serán sufridos más allá de los horizontes tradicionales de la mayoría de acuerdos existentes (ciclo político, ciclo económico, autoridades independientes sujetas a un mandato), imponiendo costes a las generaciones futuras. La inacción ante el cambio climático se traduce, presuntamente, en beneficios, en forma de mayores posibilidades de producción y consumo, para las generaciones presentes, y costes, en forma de menores posibilidades, para las futuras. Por su parte, entrar en una «transición climática» implicaría que la generación presente asume costes que no tiene incentivos directos a $\triangleright$

3 En resumen, a la definición tradicional de problema económico, de asignar unos recursos escasos a unas necesidades ilimitadas, se le une el cómo distribuir esos recursos entre colectivos y regiones, e intergeneracionalmente. 
asumir (salvo que se suponga un fuerte altruismo intergeneracional por los agentes). Surge un problema de inequidad intergeneracional.

En cierta medida, la tendencia creciente de aplicación de las metodologías que adoptan un enfoque intertemporal y desagregado se ha visto impulsada por la experiencia de los efectos de la globalización. Entre la globalización, la transición climática y la digital, como ejemplos de shocks con efectos permanentes y de gran intensidad, es la primera la que se encuentra en un mayor grado de desarrollo y, por tanto, sobre la que existe, a priori, mayor evidencia sobre sus efectos. Los procesos generados a raíz de la experiencia globalizadora pueden aportar lecciones para el caso de la «transición climática».

En muchas ocasiones, la globalización ha tenido efectos disruptivos, aislando determinados colectivos y comunidades, dando lugar a un aumento en la desigualdad.

La confianza absoluta en el proceso globalizador se apoyó en la expectativa de que los efectos negativos fuesen meramente efectos transitorios. Sin embargo, en muchas ocasiones estas hipotéticas transiciones guiadas por las asignaciones de mercado no han sido exitosas (se puede deber a distintas causas: rigideces en los mercados de factores, ineficiencia del sector financiero o falta de coordinación de los agentes a nivel internacional), dando lugar a pérdidas permanentes. La consciencia por estos problemas ha aumentado considerablemente, como se refleja en la creación del Fondo Europeo para la Adaptación a la Globalización de Trabajadores Despedidos (Claeys y Sapir, 2018) ${ }^{4}$.

\footnotetext{
4 Este fondo está centrado en prestar ayudas personales y acotadas temporalmente a los trabajadores afectados por las reestructuraciones asociadas al proceso globalizador. Se diferencia de los fondos estructurales en que estos tienen una perspectiva a largo plazo.
}

Así, la preocupación por posibles pérdidas irrecuperables y aumentos en la desigualdad asociados a la transición verde ya se encuentra en el foco del debate de política económica. Un claro ejemplo es la aprobación por parte de la Comisión Europea del Mecanismo para una Transición Justa, que incluye un fondo específico con el objetivo de suavizar el impacto de la transición a una economía climáticamente neutra.

En el camino hacia el "crecimiento económico inclusivo y sostenible» puede haber numerosos obstáculos, relacionados con los costes de transición, con el grado de aceptación y consenso social y con la dificultad de realizar compensaciones efectivas a los perdedores. Son potenciales problemas que pueden aparecer en la transición climática.

Para poder comprender esta problemática se puede acudir a Compensation, Transition Costs and Regulatory Change (Quinn y Trebilcock, 1982), en el que los autores analizan cómo un cambio regulatorio o política económica (por ejemplo, legislación medioambiental) provoca un cambio en el statu quo, dando lugar a una serie de costes de transición hasta llegar al nuevo equilibrio deseado por el legislador. Se analiza la gran dificultad, ante un cambio de este estilo, de llegar a un estado Pareto superior al inicial, habiendo ganadores y perdedores en el cambio. Reformulando el criterio de Pareto, la potencialidad de compensación es lo que permitiría que con el cambio hubiese aumento del bienestar. Bajo este criterio, la potencial compensación se justifica por razones de eficiencia. En este sentido, Quinn y Trebilcock plantean que al valorar este tipo de transiciones el criterio para identificar un aumento en el bienestar social es que las ganancias de los ganadores sean mayores que las pérdidas de los perdedores. Siendo así, a priori, la $\triangleright$ 
compensación no tendría que efectuarse para que se produjese un cambio a una situación más deseable. Ahora bien, bajo un criterio de pragmatismo político, el éxito de la medida estará supeditado a una compensación efectiva de los ganadores a los perdedores, evitando la oposición frontal de los afectados y contando con el consenso social necesario. En caso contrario, la oposición podría ser tan fuerte que la transición no se realizase y las potenciales ganancias acabasen por no materializarse. De hecho, también es defendible la efectividad de la compensación desde una óptica económica (si se considera que el aumento de la desigualdad es económicamente no deseable), al evitar o reducir las pérdidas de los perdedores.

Las problemáticas recién planteadas casan casi a la perfección con muchos de los retos planteados por la transición climática. Siendo así, puede merecer la pena detenerse en qué tipo de costes de transición pueden aparecer y a qué problemáticas se enfrentan el responsable de política económica y los afectados por las medidas. Para ello se seguirá a los autores mencionados anteriormente (Quinn y Trebilcock, 1982).

Existen dos tipos de costes de transición. Los denominados «costes de transición estrictos», entendidos como los costes de formación de nuevo capital y de aprendizaje de uso de ese nuevo capital y los «costes de capital», siendo estos los costes de abandonar capital no transferible productivo (obsolescencia técnica) y el coste de capital humano especializado en su uso.

Como retos de política económica se pueden destacar tres (siendo un mero supuesto simplificador). En primer lugar, para llegar al equilibrio deseado a largo plazo (por ejemplo, neutralidad climática) existen diversas opciones, siendo muy diferentes los costes de transición asociados a cada una de ellas. En segundo lugar, en muchas ocasiones no existe una distribución equitativa de los costes. El soporte de los costes suele estar concentrado en determinados segmentos poblacionales (por ejemplo, se prevé que los costes de transitar hacia vehículos eléctricos estén concentrados en el mundo rural más que en el urbano). Finalmente, es posible que desde que se introduce una medida hasta que se llega al equilibrio deseado ocurran distintos eventos que reconfiguren el diseño del equilibrio a largo plazo.

En definitiva, existen costes asociados a la transición, costes que pueden ser de distintos tipos y cuya presencia da lugar a ganadores y perdedores. La compensación aparece como la forma de garantizar la viabilidad de estas transiciones.

Sin embargo, no hay que obviar numerosos interrogantes que aparecen con estas compensaciones, como son: ¿refleja el pago el valor de los salarios que se dejan de percibir hasta encontrar nuevo empleo?, ¿se podrá encontrar nuevo empleo, es decir, es probable la reasignación a empleos con formación diferente a la ya adquirida?, entre otros muchos. Es más, los perdedores pueden ser escépticos ante la credibilidad sobre el pago de la compensación en las condiciones acordadas. Una vez realizado el cambio y percibidos los beneficios del mismo por los ganadores, estos no tendrán incentivos a compensar a los perdedores. La gran incertidumbre asociada a estos interrogantes hace que para los perdedores pueda ser racional oponerse al cambio de estado económico, pudiendo ser más rentable invertir recursos en la oposición al cambio y mantener el statu quo que aceptar la posible compensación.

Ahora bien, esta es solo una de las perspectivas del problema. Desde el lado opuesto, el de los ganadores, pueden encontrar $\triangleright$ 
racional garantizar una compensación cierta a los perdedores, ya que sus ganancias están condicionadas por la ausencia de oposición al cambio. Incluso, sería racional que esta oferta fuese generosa para que los beneficios potenciales de los perdedores sean mayores que sus costes y exista un encuentro de intereses entre las partes. Sin embargo, la incertidumbre asociada a este acuerdo vuelve a ser un obstáculo. Para los ganadores la compensación inicial se haría bajo la expectativa de beneficios futuros inciertos.

Teniendo en cuenta las líneas anteriores, parece que los factores intervinientes están relacionados con la eficiencia (maximizar los excedentes por el cambio), la equidad (minimizar las pérdidas localizadas en regiones o colectivos) y el pragmatismo político (con el fin de no caer en la inoperancia).

\subsection{Enfoque para el estudio}

Hasta ahora se ha desengranado el concepto de sostenibilidad. Se ha comentado cómo teóricamente es un concepto multidimensional, y cómo, desde un punto de vista práctico, plantea retos para el diseño de política económica. A continuación, se acotará el concepto de sostenibilidad a efectos del interés del estudio.

Desafortunadamente, la literatura económica se encuentra en distintos grados de desarrollo en lo que respecta a la relación entre el comercio internacional y cada uno de los pilares del concepto de sostenibilidad. En lo tocante a la perspectiva económica, la teoría económica es profusa en la interrelación entre el comercio internacional y el crecimiento económico. La línea medioambiental se encuentra, desde la década de los noventa, en una fase de gran expansión. Finalmente, el pilar social se encuentra en una fase más embrionaria, contando con escasos estudios, pero con un gran potencial de desarrollo en el futuro ${ }^{5}$.

Esta naturaleza tridimensional de la sostenibilidad es, simultáneamente, una fuente tanto de oportunidades como de posibles obstáculos a la hora de realizar estudios. Son innegables las interrelaciones y externalidades existentes entre ellos. Por tanto, de forma ideal, deberían ser tratados de forma conjunta. Sin embargo, un análisis conjunto y simultáneo de todos ellos solo es alcanzable acudiendo a un alto grado de agregación de datos, lo cual puede dificultar aislar los verdaderos canales de transmisión entre variables.

De esta forma, una posible línea de actuación podría ser estudiar cada uno de los pilares de forma aislada, manteniendo ceteris paribus el impacto sobre variables de otros pilares ( $\sin$ negar el carácter simplificador de recurrir a este enfoque). El objetivo es clarificar cada uno de los distintos canales entre las variables afectadas y, sobre todo, acceder a una mayor disponibilidad y desagregación de datos. Como aclaración, este ejercicio de aislamiento se refiere a las potenciales interrelaciones entre el pilar medioambiental y el pilar social, y no al pilar económico. Una vez hecho este ejercicio y sentados los fundamentos subyacentes a esta evaluación, se podría pasar a realizar un análisis agregado con todos los pilares incluidos.

Siendo así, a efectos del presente artículo, se circunscribirá el análisis al ámbito estrictamente medioambiental, que cuenta con un $\triangleright$

\footnotetext{
5 En caso de que el lector quiera profundizar en los estudios existentes, puede resultar de interés:

The Heterogeneous Effects Of Trade Agreements With Labor Provisions de Jacopo Timini, Nicola Cortinovis y Fernando López Vicente, 2021.

- Social Sustainability in Trade and Development Policy, de Nathan Pelletier, Eda Ustaoglu, Catherine Benoit, Greg Norris, Eckehard Rosenbaum, Alessandro Vasta y Serenella Sala, 2018.
} 
grado de desarrollo mayor que el social, y con mayor disponibilidad de datos. El objetivo es poder profundizar en mayor medida en una perspectiva concreta, sentando las bases para analizar el pilar social en futuros trabajos.

\section{Política comercial y medioambiente}

A la hora de analizar cómo el comercio afecta al medioambiente es necesario realizar una diferenciación previa. Por un lado, puede distinguirse la liberalización comercial, entendida como la firma de acuerdos comerciales y, por otro, los instrumentos concretos de política comercial orientados al medioambiente.

Esta simplificación sirve para desagregar las distintas formas en las que el comercio internacional afecta al medioambiente. La firma de acuerdos comerciales tiene una serie de objetivos, independientes de la sostenibilidad medioambiental. No obstante, la apertura comercial regional no deja de provocar una transformación de la estructura económica de los países firmantes y, como tal, tiene efectos sobre el medioambiente. Estos efectos podrían considerarse como no pretendidos, colaterales o tangenciales, pero ni mucho menos despreciables en términos de sostenibilidad medioambiental. Paralelamente, existen instrumentos de política comercial orientados a los objetivos medioambientales. Las cláusulas medioambientales son un ejemplo claro de estos instrumentos.

\subsection{Efectos de la liberalización comercial sobre el medioambiente}

¿Qué efectos produce la liberalización comercial sobre el medioambiente? La conclusión de la literatura existente es que el efecto del comercio sobre el medioambiente es ambiguo, ya que la liberalización comercial produce un conjunto de efectos positivos y negativos sobre el mismo, dando lugar a un efecto total incierto ${ }^{6}$. Este efecto se produce a través de distintos canales de transmisión que se analizan a continuación.

Para acercarse a este problema se dividirá el análisis en dos grupos de efectos, los indirectos y los directos (Martínez-Zarzoso, 2018). Los indirectos se refieren a cómo la liberalización comercial afecta al crecimiento económico y cómo ese crecimiento tiene efectos sobre la sostenibilidad medioambiental. Los directos se refieren a cómo la liberalización comercial afecta, sin intermediarios, a la sostenibilidad medioambiental.

La liberalización comercial afecta al crecimiento tanto de forma temporal como de forma permanente, generando los citados efectos indirectos sobre la sostenibilidad medioambiental.

La forma temporal se refiere al crecimiento transitorio que viene asociado, tras una apertura comercial, al hecho de que cada país se especialice en la fabricación de aquellos bienes que produce de forma más eficiente, o, planteado desde otra perspectiva, que cada producto se produzca donde "sea relativamente más barato" producirlo. Redunda en un aumento en la cantidad de bienes producida globalmente, que se detiene una vez se ha completado la transición hacia la nueva estructura de especialización productiva, en la medida que las oportunidades de arbitraje de costes se agotan. La plasmación actual de esta idea se puede observar en las cadenas globales de valor (CGV). Como apunte, aunque la $\triangleright$

6 El mayor impulso a esta línea de estudio es encarnado por Grossman y Krueger (1991), quienes utilizando un Modelo de Equilibrio General Computable hicieron una evaluación ex ante de los efectos de NAFTA sobre la estructura productiva de EE. UU., Canadá y México. 
intuición subyacente a las CGV sea un arbitraje de costes, existen numerosas líneas de estudio sobre los efectos spillover y transferencias tecnológicas asociadas a la inserción empresarial en las CGV.

Por su parte, el efecto permanente sobre el crecimiento está relacionado con el aumento del tamaño de mercado. El efecto del aumento de tamaño del mercado es un aumento de los incentivos, tanto a la competencia como a la competitividad, que genera efectos de carácter más dinámico y permanente sobre el crecimiento económico.

¿Quiere esto decir que estos efectos son independientes? Ni mucho menos. Las ganancias de eficiencia resultantes de las oportunidades de arbitraje de costes tras la firma de acuerdos comerciales y los cambios más profundos derivados del aumento del tamaño del mercado se refuerzan mutuamente, dando lugar a entornos más competitivos y eficientes que estimulan innovación y crecimiento.

¿Cómo afecta el crecimiento económico al medioambiente? ${ }^{7}$ Fundamentalmente, a través del denominado efecto escala que se analiza a continuación.

El efecto escala indica que el aumento en la actividad económica global se traduce en efectos sobre el medioambiente. Se trata de un "efecto indirecto», es decir, que valora los efectos de la liberalización sobre el medioambiente a través de sus efectos sobre la renta (o sobre el crecimiento económico).

Los efectos del crecimiento sobre el medioambiente se pueden abordar a partir de la hipótesis de la curva de Kuznets. Plantea

Al hablar de la relación entre crecimiento y medioambiente no se puede dejar de mencionar al premio Nobel de Economía de 2018 William Nordhaus. Destaca su estudio Resources as a Constraint on Growth de 1974 y, sobre todo, sus Modelos de Evaluación Integrada, especialmente la versión RICE (Regional Dynamic Integrated Model of Climate and the Economy) de 1996. que mayores niveles de renta per cápita producen efectos diferentes sobre el medioambiente en función del nivel de renta per cápita de que se trate. Esta hipotética curva tendría forma de $\mathrm{U}$ invertida. En el tramo creciente, mayor renta per cápita produce degradación medioambiental. En el tramo decreciente ${ }^{8}$, existen razones para defender que aumentos de la renta per cápita pueden producir mejoras en la calidad medioambiental, como es el hecho de que mayores niveles de renta per cápita estén asociados a preferencias más intensas por la calidad medioambiental y a una mayor demanda de servicios (a priori, menos intensivos en emisiones de gases de efecto invernadero que los productos industriales y las manufacturas) ${ }^{9}$.

Frente a este efecto escala, de naturaleza indirecta, pueden distinguirse dos efectos directos de la política comercial sobre el medioambiente: el efecto composición y el efecto técnica.

El efecto composición consiste en el cambio en la composición de la producción y en las ventajas comparativas en las economías producidas por la liberalización comercial. Parte de la ventaja comparativa como principal determinante del comercio internacional. Al analizar los efectos sobre el medioambiente se pueden distinguir dos fuentes de ventaja comparativa, que pueden operar en sentido opuesto.

Un determinante fundamental de la ventaja comparativa es la dotación de factores productivos de los países comerciantes. Bajo esta $\triangleright$

8 El modelo de estimación se basa en considerar las emisiones de $\mathrm{CO}_{2} \mathrm{u}$ otros contaminantes como variables dependientes, y como variables independientes, el nivel de renta per cápita y el cuadrado de la renta per cápita.

9 Es importante recordar que la curva de Kuznets es una hipótesis y que, como tal, lo más relevante es cuando dicha hipótesis tiene validez. Las estimaciones de la curva de Kuznets muestran que su hipótesis se corrobora en mayor grado en el caso de contaminantes locales y a corto plazo que en el caso de contaminantes globales y a largo plazo. No obstante, los resultados están sujetos a las especificaciones funcionales y a los supuestos del modelo planteados. 
premisa, los países donde el capital sea relativamente abundante exportarán bienes capital-intensivos, los cuales son más contaminantes. Por tanto, en estos países exportadores se incrementará la producción de bienes «sucios» y aumentará la contaminación.

Al tener en cuenta el medioambiente, la regulación medioambiental es considerada como una fuente de ventaja comparativa. Los países con regulaciones más laxas se beneficiarán de una mayor actividad económica y, en principio, sufrirán mayores daños medioambientales. El potencial arbitraje regulatorio medioambiental se puede traducir en una relocalización de los procesos productivos contaminantes a aquellos países que exijan menores compromisos.

En conclusión, el efecto composición dependerá de la distribución de ventajas comparativas y de la importancia de los distintos factores determinantes de la ventaja comparativa.

El efecto técnica se refiere a la mejora en la tecnología asociada a la liberalización comercial, la cual, presuntamente, tendrá un impacto positivo sobre el medioambiente. Por tanto, es necesario analizar cómo el comercio afecta a las transferencias tecnológicas y, posteriormente, cómo estas transferencias afectan al medioambiente.

La literatura considera el comercio un canal de transmisión tecnológica, la cual se espera tenga efectos positivos sobre la productividad total de los factores de los socios comerciales. Siguiendo a Inmaculada Martínez-Zarzoso y Santiago Chelala (2021) en Trade Agreements and international technology transfer, los acuerdos comerciales producen transferencias tecnológicas de forma indirecta y de forma direc$\mathrm{ta}^{10}$. El efecto técnica se refiere a los canales

10 El canal directo se refiere a la inclusión de cláusulas tecnológicas en el texto de los acuerdos comerciales. indirectos. El principal canal es la importación de bienes capital y el acceso a mercados de exportación. Existen otros canales como los flujos migratorios, la inversión directa extranjera (en adelante, IDE) o canales informales.

Una vez producida esa transferencia tecnológica, se plantea si será beneficiosa o no sobre el medioambiente. Será beneficiosa si permite que la contaminación per cápita se reduzca. Por tanto, es un beneficio medioambiental ligado a las ganancias de productividad producidas por la transferencia de tecnología. El beneficio medioambiental se basa en la reducción de la intensidad de emisión, que se traduce en una reducción de la contaminación, manteniendo constante la escala de la economía y el mix de productos producidos.

En definitiva, la literatura identifica efectos positivos y negativos, siendo el efecto total indeterminado. En función del sentido y de la intensidad de los efectos para cada país, se llegará a conclusiones diferentes. Esta ambigüedad no es sorprendente, considerando los problemas tradicionales de causalidad inversa a los que se ha tenido que enfrentar la literatura económica sobre la relación entre volumen de comercio y crecimiento (Frankel y Rose, 2005) y sobre la relación entre renta y regulación medioambiental (Frankel y Rose, 2005).

\subsection{Instrumentos de política comercial con objetivos medioambientales}

Llegados a este punto, se pasará a analizar algunas cuestiones sobre la política comercial con objetivos medioambientales. Se debe distinguir entre distintos tipos de instrumentos y su respectivo alcance o ámbito de actuación. Ahora bien, como se verá, la $\triangleright$ 
tipología de instrumentos está supeditada al ámbito de alcance de los mismos. Las cláusulas de sostenibilidad de los acuerdos comerciales son un ejemplo de estos instrumentos de política comercial, utilizadas en el ámbito regional.

Empezando por el ámbito multilateral, los esfuerzos más representativos en materia medioambiental son el Protocolo de Kyoto y el esfuerzo renovado del Acuerdo de París. Sin embargo, estos no cuentan con la política comercial como un instrumento clave en la búsqueda de la sostenibilidad medioambiental. Los problemas asociados a Kyoto son un reflejo de la dificultad de construir acuerdos efectivos y estables en el ámbito multilateral. Por esta razón, el foco en temas de gobernanza medioambiental se ha redirigido hacia el ámbito regional (Van Asselt, 2017). Paralelamente, es conocida la tendencia reciente a la regionalización de las relaciones comerciales. Tanto los acuerdos comerciales regionales como las cláusulas de sostenibilidad son un ejemplo de esta regionalización.

Dentro del abanico de opciones de política comercial, por el momento, la mayor atención se ha centrado, desde un punto de vista teórico, en los clubes climáticos y, en la práctica, en las mencionadas cláusulas de sostenibilidad medioambiental. La literatura reciente, liderada por Nordhaus, se ha centrado en la creación de clubes climáticos como forma de superar los problemas de free-rider e internalizar los costes asociados a las emisiones de gases de efecto invernadero. De hecho, existen ya propuestas prácticas en esta dirección. Por el otro, las prácticas comerciales con objetivos medioambientales se han centrado en la inclusión de cláusulas de sostenibilidad medioambiental en los acuerdos comerciales regionales.
Como cuestión introductoria, es necesario explicar los problemas asociados a la conceptualización de la calidad medioambiental y, en particular, de la emisión de gases efecto invernadero (en adelante, EGEI).

\subsubsection{Calidad medioambiental}

Para poder comprender la interrelación entre la política comercial y el medioambiente es necesario conceptualizar el problema al que se hace frente. La literatura económica muestra que las características de la calidad medioambiental de bien público global requieren una actuación coordinada a nivel mundial. Alcanzar la sostenibilidad medioambiental es considerado un reto de «acción colectiva» (Olson, 1971). La versión tradicional de esta teoría muestra que los agentes participarán en la solución de los problemas de acción colectiva tanto si el tamaño del grupo del que forman parte es lo suficientemente pequeño (evitar el problema de free-rider) como si existe alguna herramienta que altere la estructura de pagos inicial (p. ej., incentivos o sanciones para garantizar la estabilidad del acuerdo).

Como muestra la teoría económica, en la provisión de bienes públicos aparece un problema de free-rider. En el ámbito medioambiental el comportamiento de free-rider se basa en disfrutar de los beneficios de la reducción de EGEI de otros países sin realizar una política de mitigación a nivel nacional. Por tanto, es posible disfrutar de los beneficios sin incurrir en costes. A este problema de eficiencia se le une un problema de equidad, en la medida que los beneficios y costes no tienen por qué estar uniformemente distribuidos. Se generan problemas de desigualdad geográfica (entre países), entre generaciones y entre colectivos (a priori, mayor esfuerzo relativo realizado por consumidores y pymes). 
Es importante diferenciar entre contaminación global y local. Poder defender la existencia de un problema de free-rider, en el contexto de calidad medioambiental, está sujeto a acotar el análisis al caso de contaminación global, de forma que la mayoría de los daños medioambientales sufridos son producidos desde el extranjero y los causados son sufridos en otros países. Esta simplificación se justifica en que el estudio de la interrelación entre política comercial y medioambiente tiene como uno de sus objetivos principales fijar un precio global al carbono.

Se ha planteado la calidad medioambiental, a nivel global, como un bien público global (BPG). No obstante, como se verá posteriormente a propósito del análisis de acuerdos comerciales de la UE, la calidad medioambiental puede concretarse de múltiples formas. Una de sus proxies principales es la reducción de EGEI en la lucha contra el cambio climático (es más, este es el objetivo principal del Acuerdo de París). En concreto, la lucha contra el cambio climático mediante la reducción de las EGEI es conceptualizable microeconómicamente como un problema de externalidad. ¿Es inconsistente la caracterización de la calidad medioambiental como BPG y de la reducción de EGEI como externalidad? Ni mucho menos. Es importante recordar la interrelación entre el concepto de bien público y de externalidad, sobre todo en un marco de interdependencia estratégica. La búsqueda de la calidad medioambiental mediante la lucha contra el cambio climático se puede considerar simultáneamente un BPG, por la falta de incentivos a participar en acuerdos y cooperar, y una externalidad, ya que, en gran medida, esa cooperación se instrumentaliza internalizando todos los costes asociados a la emisión de carbono (como gas de efecto invernadero más representativo económicamente).

\subsubsection{Clubes climáticos}

Una vez fijado el marco de actuación, ¿es posible fijar algún tipo de acuerdo que solucione el problema de free-rider a nivel global? Siguiendo a Nordhaus (2015), aparece una complicación particular asociada al carácter global de la calidad medioambiental. En el caso de bienes públicos de ámbito nacional, es factible fijar mecanismos y acuerdos que garanticen una provisión eficiente del bien público. Sin embargo, el ordenamiento jurídico internacional dificulta esta posibilidad. Formar parte de acuerdos internacionales requiere el consentimiento de los Estados, siendo los acuerdos por esencia voluntarios. Recordando las características de contexto de bien público global, en el que los agentes que soportan los costes son diferentes de los que disfrutan los beneficios, el consentimiento a entrar en potenciales acuerdos globales será difícilmente creíble. Ante la ausencia de recompensas o castigos, se llegará a la inefectividad por el problema de free-rider.

La descripción anterior es una representación simplificada de los problemas del Protocolo de Kyoto. El plano multilateral, con un gran número de participantes, dificulta la efectividad de los compromisos y aumenta el riesgo de inestabilidad. En términos de dilema de prisionero, se llegó a un equilibrio de Nash no cooperativo, en el que el nivel de mitigación fue muy inferior al nivel de eficiencia (cooperación).

Como respuesta a estos problemas aparece la idea de «clubes climáticos», basados en actuación regional y en el uso de la política comercial para garantizar el éxito en la mitigación. Su sustento teórico se encuentra en la teoría de los clubes (Buchanan, 1965). Los clubes climáticos son definidos como coaliciones limitadas entre Estados (o agentes que no sean Estados), que promueven la cooperación en $D$ 
actividades climáticas, otorgan beneficios exclusivos a sus participantes a cambio de contribuciones y establecen algún tipo de control. Entrando en el ámbito comercial, el principal beneficio para los participantes en el club climático es el acceso preferencial a mercados de otros países («zanahoria») (Green y Epps, 2009).

Nordhaus defiende el diseño de "coaliciones» que introduzcan «sanciones externas» («palo»). Se entiende por sanción externa a aquella que se impone a una relación comercial independiente de la estructura de pagos subyacente a la participación o no participación en el club climático. Por tanto, mientras que en la estructura de pagos subyacente a cumplir o no cumplir los objetivos del Protocolo de Kyoto no había incentivos a cumplir los compromisos (cooperar), en el caso de un club climático, con la implementación de sanciones en el ámbito comercial, se incentiva la cooperación (participación en el club). Se llega a un equilibrio de Nash en coaliciones eficiente (al ser el nivel de mitigación superior al de no cooperación) y estable (al ser un equilibrio de Nash perfecto en subjuegos, ya que en todo momento los beneficios de pertenecer al club son superiores a sus costes).

Existen reticencias respecto a la implementación de las sanciones externas por la potencialidad de provocar guerras comerciales. Por esta razón, los defensores más acérrimos de la formación de clubes climáticos consideran que deberían ser Estados Unidos, la Unión Europea y China los que formasen esa coalición. Esto permitiría evitar tensiones comerciales entre los principales actores comerciales a nivel mundial. A su vez, haría que la «zanahoria» por formar parte del club climático preponderase sobre el «palo». Es decir, es razonable esperar que el resto de países prefiera tener acceso a comerciar con los principales actores comerciales del mundo y o bien hacer frente a la sanción externa del club o decidir participar en él.

Respecto a los clubes climáticos se debe comentar brevemente la forma de esas sanciones externas y en qué consiste exactamente la cooperación de formar parte del club. Es decir, analizar cómo son los instrumentos que llevan a los países a formar parte del club y, una vez dentro, en qué consisten sus compromisos.

En primer lugar, en qué consisten las sanciones externas. Pueden ser obligaciones de carbono o aranceles uniformes, en función del objetivo concreto buscado.

Las obligaciones de carbono consisten en establecer aranceles a los bienes importados desde los no participantes en relación con su contenido de carbono (o bien en un marco de cap and trade, en el que los importadores compren derechos de emisión que cubran el contenido de carbono de las importaciones). El objetivo de este régimen es evitar la fuga de carbono a países con menores impuestos o regulaciones sobre el carbono, permitiendo establecer las mismas condiciones de competencia para todos los países y reducir el nivel de emisiones.

El mecanismo de aranceles uniformes se basa en gravar de forma uniforme toda importación de no participantes en el club, independientemente de su contenido en carbono. Su objetivo es aumentar la participación en el club.

En segundo lugar, la cooperación asociada a participar en el club climático consiste en establecer un precio al carbono que refleje su «coste social» dentro de los países miembros de la coalición (mediante instrumentos pigouvianos, un mercado de derechos de emisión, o fórmulas mixtas). A mayor número de participantes, mayor coste social del carbono y, $\triangleright$ 
por tanto, mayor precio del carbono. A priori, cuanto mayor sea el número de participantes, más cerca se estará de la tasa de reducción eficiente de carbono. Sin embargo, cuanto más caro sea el carbono, menores incentivos a participar en la coalición, aumentando el riesgo de inestabilidad. Aparece, pues, un trade-off entre efectividad y estabilidad. Es lo que Nordhaus define como «paradoja de las coaliciones pequeñas» (Nordhaus, 2015). En definitiva, la coalición estable tendrá un número reducido de participantes, la cual llevará a un nivel de mitigación ligeramente mejor que el de equilibrio no cooperativo.

Desde la perspectiva de la UE, se puede analizar tanto la cuestión de los clubes climáticos como el uso de la política comercial con objetivos medioambientales.

En lo que respecta a los clubes climáticos, se pueden distinguir dos perspectivas. En primer lugar, la propia UE puede ser considerada un club climático, en la medida en que cuenta con participación limitada, existe un sistema de contribuciones, permite el acceso exclusivo a su régimen de comercio de derechos de emisión (ETS, por sus siglas en inglés) y es apoyada por un sistema de revisión y control. Por otro, la eventual creación de un club climático entre los principales actores comerciales mundiales, aunque aún en la lejanía, parece encaminada en la dirección adecuada.

En lo que respecta al uso de la política comercial, la UE puede acudir tanto a la política comercial autónoma como a la convencional. El uso más probable de la autónoma con estos fines sería mediante el establecimiento de un mecanismo de ajuste en frontera por emisiones de carbono compatible con la OMC (Comisión Europea, 2021). Es una cuestión actualmente en vías de negociación dentro de la UE.
En la política comercial convencional, el uso de instrumentos comerciales medioambientales se vertebra mediante la inclusión de cláusulas medioambientales, lo cual puede ser interpretado como una forma de hacer partícipes del club climático europeo a los socios comerciales de la UE (es importante notar que para ello estas cláusulas precisan de un mecanismo de control que lleve aparejado un mecanismo sancionador; en caso contrario, son solo un instrumento de cooperación).

\subsubsection{Cláusulas de sostenibilidad medioambiental}

Anteriormente se analizaron los efectos que la liberalización comercial tiene sobre el medioambiente, distinguiendo entre efectos indirectos y efectos directos. Una de las formas más recurrentes de liberalización comercial, sobre todo en las últimas décadas, es la regional, es decir, la instrumentada en torno a acuerdos regionales. Particularmente, en las últimas décadas han proliferado los conocidos como Acuerdos de Nueva Generación (en adelante, ANG), caracterizados por involucrar a un número reducido de socios comerciales, pero para abordar una gran amplitud de materias $y$, en general, en gran profundidad. La UE se ha convertido en un gran impulsor de este tipo de acuerdos, incluyendo en ellos un capítulo relacionado con la sostenibilidad medioambiental. Este capítulo incluye, pues, el instrumento de política comercial conocido como cláusulas de sostenibilidad medioambientales.

Como ya se ha comentado, el objetivo del presente artículo es acercarse a la cuestión sobre si las cláusulas de sostenibilidad medioambiental en los acuerdos comerciales de la UE tienen efectos sobre el medioambiente. Para abordar esta cuestión se analizarán, en $\triangleright$ 
primer lugar, los distintos canales a través de los cuales estas cláusulas pueden tener efectos sobre el medioambiente $y$, en segundo lugar, una descripción de la tipología de cláusulas existentes.

Con relación a los canales a través de los cuales las cláusulas pueden afectar al medioambiente, es preciso encuadrar la cuestión. Recientemente, los mecanismos de gobernanza en ámbitos comerciales y climáticos ${ }^{11}$ parecen haberse dirigido hacia el marco regional, en contraste con el multilateral (Van Asselt, 2017). Tanto los ANG como las cláusulas de sostenibilidad son un ejemplo de esta tendencia. Se podría pensar que la literatura sobre comercio y medioambiente, al hablar de liberalización comercial, se identifica más con un plano multilateral. Por esta razón, con posterioridad al planteamiento de los efectos escala, técnica y composición, surgieron estudios que analizaron los efectos de la pertenencia a un acuerdo regional sobre el medioambiente.

Estos estudios reflejaron dos conclusiones principales. La primera es que la pertenencia a un acuerdo regional, sin distinguir la inclusión o no de cláusulas medioambientales, no parece tener un efecto directo sobre el medioambiente. Solo el efecto indirecto a través de mayor comercio y crecimiento. La otra, y de enorme relevancia para el objetivo del artículo, es que al distinguir si el acuerdo regional incluye o no provisiones medioambientales, se observa cómo los que sí las incluyen tienen efectos directos sobre el medioambiente.

A raíz de la conclusión de la importancia de incluir cláusulas medioambientales, surge la

\footnotetext{
1 No se puede olvidar la reciente aprobación del Acuerdo de París en cuestiones climáticas. Sin embargo, el propio acuerdo promueve la instauración de coaliciones cooperativas en un nivel regional. A su vez, la mayor relevancia de la idea de clubes climáticos hace pensar que el futuro de la gobernanza climática se encuentra en el ámbito regional.
}

necesidad de profundizar en los canales a través de los cuales se produce esta mejora en la calidad medioambiental, independientes del efecto a través del comercio y de la renta. Los canales principales son la aprobación de regulación medioambiental más estricta, la creación de esquemas de valoración del impacto medioambiental, la creación de instituciones orientadas a objetivos medioambientales o la expansión de preocupaciones medioambientales.

Con todo, es necesario realizar una puntualización. Es posible que surja un problema de «endogeneidad o causalidad inversa» a la hora de analizar los acuerdos regionales que incluyen cláusulas medioambientales y los canales a través de los cuales estas cláusulas inciden en el medioambiente. Aplicándolo al caso de los acuerdos de la UE, el análisis anterior considera que, una vez se firma el acuerdo regional con cláusula, es más probable que los socios comerciales de la UE aprueben regulación medioambiental, por ejemplo. Es innegable que esta es una posibilidad. Ahora bien, también parece razonable afirmar que la inclusión o no de provisiones medioambientales y, además, el tipo de cláusula y su grado de concreción pueden estar condicionadas por la predisposición de partida del socio comercial a aceptar compromisos medioambientales. Es decir, un país será más propenso a aceptar la inclusión de cláusulas medioambientales ambiciosas cuando el esfuerzo a realizar para cumplirlas sea menor (mayor regulación medioambiental tenga aprobada, mayor desarrollo institucional orientado al medioambiente...) o mayor sea su disponibilidad previa a realizarlo (por la orientación de las preferencias de su población hacia una mayor calidad ambiental).

La conclusión fundamental es que, a priori, la inclusión o no de cláusulas, con quién se $\triangleright$ 
CUADRO 1

OBJETIVOS MEDIOAMBIENTALES SEGÚN EL TIPO DE CLÁUSULA

\begin{tabular}{|c|c|c|c|}
\hline & Claúsulas & Contenido & Finalidad \\
\hline Grupo 1 & Referencia general & Alta protección medioambiental & Regulación medioambiental \\
\hline Grupo 2 & Cooperación & & \\
\hline Grupo 3 & Prohibición de relajación de regulación medioambiental & Liberalización en sectores verdes & Evaluación impacto \\
\hline
\end{tabular}

Fuente: elaboración propia, a partir de Content Of Deep Trade Agreements; Environmental Laws (https://datacatalog.worldbank.org/dataset/ content-deep-trade-agreements).

incluyen y de qué tipo son, no es aleatoria. Por tanto, existen incentivos a aceptar o rechazar su inclusión. Como incentivos principales a incluirlas se encuentran la consecución del objetivo de desarrollo sostenible o garantizar el level playing field (evitar arbitraje regulatorio medioambiental). Por su parte, como ya se ha comentado, los principales incentivos a rechazarlas son la percepción de que pueden actuar como barreras a las exportaciones o el hecho de que es necesaria una importante movilización de recursos para el cumplimiento de los compromisos medioambientales.

Existen numerosos tipos de cláusulas de sostenibilidad. Además, no existe un criterio único de clasificación. Se planteará una de las múltiples posibles clasificaciones, compatible con la diferenciación realizada por el Banco Mundial (Content of Deep Trade Agreements, Environmental Laws).

Se pueden distinguir tres tipos de cláusulas: las que se refieren al medioambiente en general, las que consagran una cooperación profunda en materia de cambio climático y medioambiente y, finalmente, las que facilitan el comercio e inversión en sectores medioambientalmente relevantes (Cuadro 1).

El primer grupo se refiere a provisiones relacionadas con el medioambiente en general. Atendiendo a su localización en el acuerdo, pueden ser provisiones incluidas en el capítulo relacionado con el desarrollo sostenible y el medioambiente o que estén en otros capítulos del acuerdo ${ }^{12}$. Respecto a su contenido, se puede diferenciar entre referencias generales al medioambiente, provisiones que consagran un alto grado de protección medioambiental o el compromiso de introducir y garantizar el cumplimiento de regulación medioambiental.

El segundo grupo busca consagrar una cooperación sólida en la lucha contra el cambio climático entre las partes signatarias del acuerdo. Esta cooperación se materializa en compromisos de establecer esfuerzos compartidos y/o reafirmaciones de los compromisos existentes en los acuerdos climáticos multilaterales.

El tercer grupo se refiere a cláusulas que buscan fomentar el comercio y la inversión en sectores relevantes para el clima. Hay dos tipos de cláusulas de este grupo de particular interés: por una parte, las que fomentan la liberalización del comercio en bienes y servicios verdes, y, por otra, las que prohíben la relajación de los compromisos medioambientales como forma de fomentar el comercio. Asimismo, siguiendo los criterios de categorización de cláusulas del Banco Mundial, en este grupo se incluyen también las cláusulas que estipulan la obligación de realizar una evaluación del impacto del acuerdo sobre el desarrollo sostenible de los socios comerciales. La consideración de esta cláusula en el análisis se basa $\triangleright$

12 Existen cláusulas que, sin estar incluidas en el capítulo de desarrollo sostenible, tienen incidencia sobre el medioambiente. Por ejemplo, cláusulas de derechos de propiedad intelectual, contratación pública, inversión, mecanismos de resolución de conflictos... 
en su estrecha relación con el objetivo último del artículo.

\subsubsection{Cláusulas medioambientales en los acuerdos comerciales de la UE y comparación con los de EE. UU. y China}

Una vez descritas las cláusulas concretas que serán de interés, se pasará a comentar su tratamiento por los acuerdos comerciales de la UE, de acuerdo a la base de datos Content of Deep Trade Agreements, Environmental Laws del Banco Mundial, anteriormente mencionada. Es necesario realizar una serie de aclaraciones previas para facilitar el análisis.

La primera es que la base incluye los acuerdos firmados hasta 2015, razón por la que se han añadido algunos de los acuerdos más relevantes firmados por la UE desde 2015. De hecho, será interesante ver cómo a partir de 2015 aparecen cambios significativos en alguna cláusula.

Las cláusulas se clasificarán en tres grupos, siguiendo rigurosamente la clasificación teórica planteada anteriormente. El Grupo 1 se identifica con las cláusulas que versan sobre el medioambiente de forma general. El Grupo 2, con las que consagran la voluntad de cooperación en materia de desarrollo sostenible medioambiental. El Grupo 3 hace referencia al comercio de productos medioambientales y la inclusión de evaluaciones ex post del impacto de los acuerdos sobre el desarrollo sostenible de los signatarios.

Las nomenclaturas « 1 » « 0 » se refiere a si un acuerdo concreto incluye o no una cláusula determinada. Tienen significado puramente descriptivo, no cuantitativo. Se están cruzando dos tipos de datos, el acuerdo y un tipo particular de cláusulas: «1» significa que el acuerdo en cuestión incluye la cláusula a la que se hace referencia; «0», en sentido contrario, que el acuerdo no la incluye.

Las principales conclusiones del análisis que se realiza a continuación pueden resumirse en que la UE, desde los años noventa, está llevando a cabo una política de inclusión de cláusulas medioambientales en sus acuerdos comerciales, orientadas hacia la alta preocupación medioambiental, a evitar el uso de la relajación de la regulación medioambiental como ventaja competitiva y con una tendencia creciente a la evaluación de impacto de las cláusulas medioambientales. Paralelamente, EE. UU. sigue una pauta similar, aunque con una mayor tendencia a la convergencia regulatoria. Tanto la UE como EE. UU. presentan un enfoque mucho más ambicioso que China, donde las cláusulas son de carácter más generalista.

Como punto de partida, de los 40 acuerdos considerados, 32 incluyen un capítulo sobre desarrollo sostenible y/o medioambiente. Como patrón general, son cuestiones tratadas en los acuerdos comerciales de la UE. Una cuestión significativa puede ser que, de los ocho acuerdos que no incluyen un capítulo, siete fueron firmados antes de 2004, y que, de esos, seis se acordaron en la década de los noventa o antes. Por tanto, se puede pensar que, a partir de un determinado momento, la UE adoptó la política de incluir estas cuestiones en sus acuerdos comerciales. Se podría pensar que su mera inclusión no está, por tanto, sujeta al tipo de socio comercial. No obstante, previsiblemente, la concreción y la ambición de los objetivos sí estarán condicionadas al tipo de socio comercial. Para apoyar estas afirmaciones, el Cuadro 2 incluye el año de aprobación de los distintos acuerdos comerciales (en general se ha incluido el año a partir del cual el acuerdo fue ratificado y entró en vigor; sin embargo, en otros casos, principalmente en muchos de los acuerdos firmados $\triangleright$ 
a partir de 2015, se refiere a la fecha en que se alcanzó un «acuerdo de principios», al no haber sido ratificados por el momento).

El Grupo 1 también revela algunas conclusiones interesantes. Comparando las provisiones de alguna «referencia general» al medioambiente y «alta protección medioambiental», se observa una gran cantidad mayor del segundo tipo. A priori, se podría pensar que la no inclusión universal de «referencias generales» al medioambiente no es per se negativa en la búsqueda de la sostenibilidad medioambiental. Sin embargo, en la medida que el grado de concreción de «alta protección medioambiental» es mucho mayor, se observa una preocupación generalizada por consagrar la protección medioambiental como objetivo fundamental en los acuerdos comerciales.

Por otro lado, la inclusión de cláusulas que promueven la armonización regulatoria es residual. La norma es la consagración del derecho a regular en el ámbito medioambiental por parte de los Estados, pudiendo establecer el nivel de protección medioambiental que consideren oportuno. Eso sí, sin utilizar la regulación medioambiental ni como medida proteccionista de facto ni su relajación como forma de fomentar el comercio.

Como muestra el Cuadro 3, la consagración explícita de la cooperación medioambiental no aparece en la mayoría de los acuerdos de la UE considerados. Sin embargo, no se debe interpretar necesariamente como una minusvaloración por parte de la UE de su importancia. Se puede pensar que la propia esencia de estas cláusulas, normalmente plasmadas de forma genérica, hace que deban ser consideradas de forma conjunta con las otras cláusulas medioambientales incluidas en el acuerdo. Por tanto, su no inclusión no se tiene por qué interpretar como una menor preocupación por el medioambiente, sino como una plasmación diferente de dicha preocupación.

Como posible justificación de esta hipótesis, dentro de todos los acuerdos que no hacen mención explícita a la «cooperación», quince de ellos $^{13}$ incluyen otras provisiones que reflejan preocupaciones sólidas por el medioambiente, principalmente cláusulas que consagran la necesidad de «alta protección medioambiental».

Finalmente, el Cuadro 4 permite analizar las cláusulas que están más ligadas al ámbito estricto del comercio. Se observa cómo, dentro del uso de cláusulas medioambientales con fines rigurosamente comerciales, la atención de la UE se centra en evitar posibles arbitrajes regulatorios, fijando un level-playing field. Se busca evitar la utilización de la regulación medioambiental como fuente de ventaja comparativa. Un ejemplo representativo es el acuerdo entre la UE y Reino Unido, en el cual evitar prácticas desleales es uno de los principales objetivos de la UE, no solo en el ámbito medioambiental.

A su vez, es destacable el escaso uso de cláusulas que fomenten la liberalización de sectores verdes, lo cual podría ser un obstáculo al efecto técnica. No obstante, ha de tenerse en cuenta la proliferación de cláusulas tecnológicas, que tienen como objetivo principal dicha transferencia.

Finalmente, la inclusión del compromiso de realizar una evaluación del impacto de las cláusulas es aún residual, pero en una clara tendencia creciente. Como muestra el Cuadro 4, seis acuerdos incluyen esa provisión. Es un claro reflejo de la intención de la UE de realizar un seguimiento de la implementación de las provisiones de sus acuerdos, con vistas a poder $\triangleright$

13 Son los acuerdos con Albania, América Central, Chile, Colombia, Perú, Egipto, Israel, Jordania, Corea del Sur, Marruecos, San Marino, Sudáfrica, Siria, Túnez, Vietnam y Reino Unido. 
CUADRO 2

ACUERDOS COMERCIALES DE LA UE. CLÁUSULAS DEL GRUPO 1*

\begin{tabular}{|c|c|c|c|c|}
\hline Acuerdos comerciales de la UE & $\begin{array}{l}\text { Capítulo sobre } \\
\text { medioambiente }\end{array}$ & $\begin{array}{c}\text { Referencia } \\
\text { general }\end{array}$ & $\begin{array}{l}\text { Alta protección } \\
\text { medioambiental }\end{array}$ & $\begin{array}{c}\text { Regulación } \\
\text { medioambiental }\end{array}$ \\
\hline UE - Albania (2009) ............. & 0 & 0 & 1 & 0 \\
\hline UE - Argelia (2005) .... & 1 & 0 & 1 & 0 \\
\hline UE - Andorra (1991) & 0 & 0 & 0 & 0 \\
\hline UE - Bosnia y Herzegovina (2015) & 1 & 0 & 1 & 0 \\
\hline UE - Camerún (2014) .... & 1 & 0 & 0 & 0 \\
\hline UE - Países Cariforum (2008) & 1 & 1 & 1 & 1 \\
\hline UE - América Central (2013) & 1 & 1 & 1 & 1 \\
\hline UE - Chile (2003) & 1 & 0 & 1 & 0 \\
\hline UE - Colombia y Perú (2013) ... & 1 & 1 & 1 & 1 \\
\hline UE - Costa de Marfil (2015) & 1 & 0 & 0 & 0 \\
\hline UE - Países del Sur y Este de África (2007) .............. & 1 & 0 & 1 & 0 \\
\hline 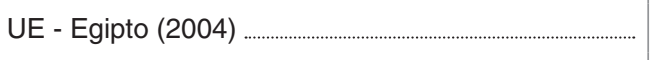 & 1 & 0 & 1 & 0 \\
\hline UE - Islas Feroe (1997) & 0 & 0 & 0 & 0 \\
\hline UE - Macedonia del Norte (2004) & 1 & 0 & 1 & 0 \\
\hline UE - Georgia (2015) & 1 & 1 & 1 & 1 \\
\hline UE - Islandia (1994) & 0 & 0 & 0 & 0 \\
\hline UE - Israel (2000) & 1 & 0 & 1 & 0 \\
\hline UE - Jordania (2002) ................. & 1 & 0 & 1 & 0 \\
\hline UE - Corea (2015) & 1 & 1 & 1 & 1 \\
\hline UE - Líbano (2006) ....... & 0 & 0 & 0 & 0 \\
\hline UE - Montenegro (2010) & 1 & 0 & 1 & 0 \\
\hline UE - Marruecos (2000) & 1 & 0 & 1 & 0 \\
\hline UE - Noruega (1994) & 0 & 0 & 0 & 0 \\
\hline UE - Papúa Nueva Guinea - Fiji (2013) ................. & 1 & 0 & 0 & 0 \\
\hline UE - Rep. de Moldavia (2015) ......................... & 1 & 1 & 1 & 1 \\
\hline 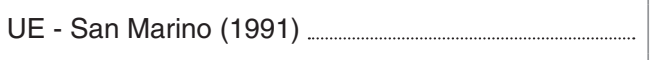 & 1 & 0 & 1 & 0 \\
\hline 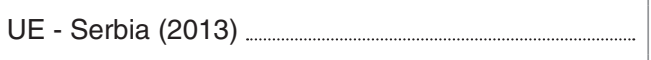 & 1 & 1 & 1 & 0 \\
\hline 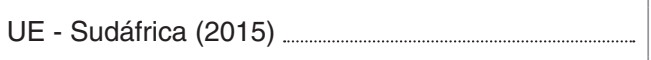 & 1 & 0 & 1 & 0 \\
\hline UE - Suiza \& Liechtenstein (1973) ............. & 0 & 0 & 0 & 0 \\
\hline UE - Siria (2003) .... & 1 & 0 & 1 & 0 \\
\hline UE - Túnez (1998) ....................................... & 1 & 0 & 1 & 0 \\
\hline UE - Ucrania (2015) & 1 & 1 & 1 & 1 \\
\hline UE - Turquía (1995) ..................................... & 0 & 0 & 0 & 0 \\
\hline UE - Japón (2019) & 1 & 0 & 0 & 0 \\
\hline UE - Singapur (2019) & 1 & 1 & 0 & 0 \\
\hline UE - Canadá (2017) & 1 & 1 & 1 & 0 \\
\hline UE - Mercosur (2019) & 1 & 1 & 1 & 0 \\
\hline UE - Vietnam (2020) ................. & 1 & 0 & 0 & 0 \\
\hline UE - Reino Unido (2020) & 1 & 1 & 1 & 0 \\
\hline UE - México (2018) & 1 & 1 & 1 & 0 \\
\hline Total general & 32 & 13 & 27 & 7 \\
\hline
\end{tabular}


CUADRO 3

ACUERDOS COMERCIALES DE LA UE. CLÁUSULAS DEL GRUPO 2

\begin{tabular}{|c|c|c|}
\hline Acuerdos comerciales de la UE & $\begin{array}{l}\text { Capítulo sobre } \\
\text { medioambiente }\end{array}$ & Cooperación \\
\hline UE - Albania .................................................. & 0 & 1 \\
\hline UE - Argelia ........... & 1 & 0 \\
\hline UE - Andorra & 0 & 0 \\
\hline UE - Bosnia y Herzegovina ....... & 1 & 1 \\
\hline 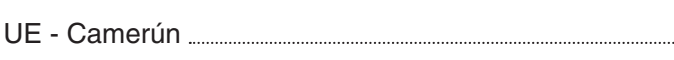 & 1 & 0 \\
\hline UE - Países Cariforum & 1 & 1 \\
\hline UE - América Central & 1 & 0 \\
\hline UE - Chile & 1 & 0 \\
\hline UE - Colombia y Perú & 1 & 0 \\
\hline UE - Costa de Marfil .............................. & 1 & 0 \\
\hline 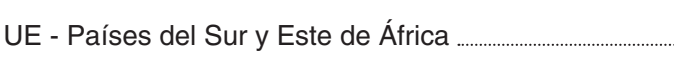 & 1 & 0 \\
\hline UE - Egipto & 1 & 0 \\
\hline UE - Islas Feroe & 0 & 0 \\
\hline UE - Macedonia del Norte & 1 & 1 \\
\hline UE - Georgia & 1 & 1 \\
\hline UE - Islandia ............. & 0 & 0 \\
\hline UE - Israel & 1 & 0 \\
\hline UE - Jordania .................. & 1 & 0 \\
\hline UE - Corea & 1 & 0 \\
\hline 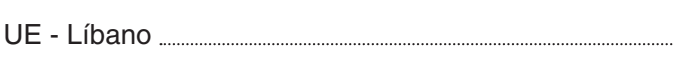 & 0 & 0 \\
\hline UE - Montenegro & 1 & 1 \\
\hline UE - Marruecos & 1 & 0 \\
\hline UE - Noruega & 0 & 0 \\
\hline UE - Papúa Nueva Guinea - Fiji ............................ & 1 & 0 \\
\hline UE - Rep. de Moldavia & 1 & 1 \\
\hline UE - San Marino & 1 & 0 \\
\hline UE - Serbia & 1 & 1 \\
\hline UE - Sudáfrica & 1 & 0 \\
\hline UE - Suiza \& Liechtenstein ............. & 0 & 0 \\
\hline UE - Siria $\ldots \ldots \ldots$ & 1 & 0 \\
\hline UE - Túnez ........................ & 1 & 0 \\
\hline UE - Ucrania & 1 & 1 \\
\hline 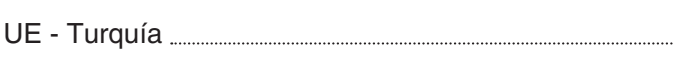 & 0 & 0 \\
\hline UE - Japón & 1 & 1 \\
\hline UE - Singapur & 1 & 1 \\
\hline UE - Canadá ……………......... & 1 & 1 \\
\hline UE - Mercosur & 1 & 1 \\
\hline UE - Vietnam ....................................... & 1 & 0 \\
\hline UE - Reino Unido & 1 & 0 \\
\hline UE - México & 1 & 1 \\
\hline Total general & 32 & 14 \\
\hline
\end{tabular}


CUADRO 4

ACUERDOS COMERCIALES DE LA UE. CLÁUSULAS DEL GRUPO 3

\begin{tabular}{|c|c|c|c|c|}
\hline Acuerdos comerciales de la UE & $\begin{array}{l}\text { Capítulo sobre } \\
\text { medioambiente }\end{array}$ & $\begin{array}{l}\text { Relajación de } \\
\text { regulación } \\
\text { medioambiental }\end{array}$ & $\begin{array}{c}\text { Liberalización } \\
\text { en sectores } \\
\text { verdes }\end{array}$ & $\begin{array}{c}\text { Evaluación } \\
\text { del } \\
\text { impacto }\end{array}$ \\
\hline UE - Albania & 0 & 0 & 0 & 0 \\
\hline UE - Argelia .............. & 1 & 0 & 0 & 0 \\
\hline UE - Andorra & 0 & 0 & 0 & 0 \\
\hline UE - Bosnia y Herzegovina & 1 & 0 & 0 & 0 \\
\hline UE - Camerún & 1 & 1 & 0 & 0 \\
\hline 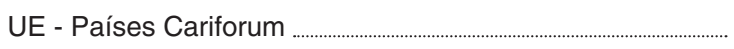 & 1 & 1 & 1 & 0 \\
\hline UE - América Central & 1 & 1 & 0 & 0 \\
\hline UE - Chile & 1 & 0 & 0 & 0 \\
\hline UE - Colombia y Perú & 1 & 1 & 0 & 0 \\
\hline UE - Costa de Marfil & 1 & 0 & 0 & 0 \\
\hline 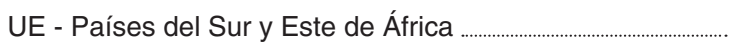 & 1 & 0 & 0 & 0 \\
\hline UE - Egipto & 1 & 0 & 0 & 0 \\
\hline UE - Islas Feroe & 0 & 0 & 0 & 0 \\
\hline UE - Macedonia del Norte & 1 & 0 & 0 & 0 \\
\hline UE - Georgia & 1 & 1 & 0 & 0 \\
\hline UE - Islandia & 0 & 0 & 0 & 0 \\
\hline UE - Israel & 1 & 0 & 0 & 0 \\
\hline UE - Jordania ................... & 1 & 0 & 0 & 0 \\
\hline UE - Corea & 1 & 1 & 0 & 0 \\
\hline 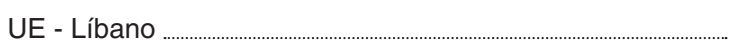 & 0 & 0 & 0 & 0 \\
\hline UE - Montenegro & 1 & 0 & 0 & 0 \\
\hline UE - Marruecos …………………………………….... & 1 & 0 & 0 & 0 \\
\hline UE - Noruega & 0 & 0 & 0 & 0 \\
\hline 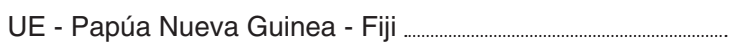 & 1 & 0 & 0 & 0 \\
\hline 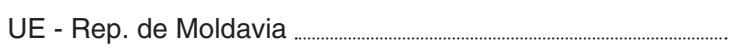 & 1 & 1 & 0 & 0 \\
\hline UE - San Marino & 1 & 0 & 0 & 0 \\
\hline UE - Serbia & 1 & 0 & 0 & 0 \\
\hline UE - Sudáfrica & 1 & 0 & 0 & 0 \\
\hline UE - Suiza \& Liechtenstein ...................................... & 0 & 0 & 0 & 0 \\
\hline UE - Siria & 1 & 0 & 0 & 0 \\
\hline UE - Túnez …………………….......... & 1 & 0 & 0 & 0 \\
\hline UE - Ucrania & 1 & 1 & 0 & 0 \\
\hline UE - Turquía ………………........... & 0 & 0 & 0 & 0 \\
\hline 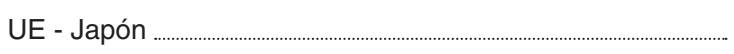 & 1 & 1 & 1 & 1 \\
\hline UE - Singapur & 1 & 1 & 1 & 1 \\
\hline UE - Canadá & 1 & 1 & 1 & 1 \\
\hline UE - Mercosur & 1 & 1 & 0 & 1 \\
\hline UE - Vietnam & 1 & 1 & 1 & 1 \\
\hline UE - Reino Unido & 1 & 1 & 0 & 1 \\
\hline 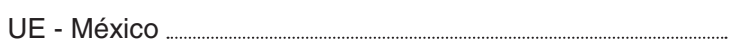 & 1 & 1 & 0 & 0 \\
\hline Total general & 32 & 15 & 5 & 6 \\
\hline
\end{tabular}


mejorar el diseño de sus acuerdos comerciales y aumentar su efectividad.

Una vez analizado el uso que la UE está dando a las cláusulas medioambientales, puede ser interesante, a efectos comparativos, comentar el uso que hacen otros actores comerciales relevantes de la importancia de estas cláusulas, como es el caso de Estados Unidos o de China. Para ello, se hará uso de la misma base de datos del Banco Mundial.

En el caso de EE. UU., se observa una serie de patrones (Cuadro 5). Incluye de forma generalizada tanto un capítulo sobre medioambiente como una referencia general al mismo, así como el compromiso de una alta protección medioambiental. Al igual que la UE, el uso de la cláusula de cooperación es mucho menor (en este caso residual). La no utilización de esta cláusula tampoco parece que deba interpretarse como una menor preocupación por cuestiones medioambientales.

Un factor diferenciador entre el caso de la UE y de EE. UU. es el uso que hacen de las cláusulas de cooperación y armonización regulatoria. A simple vista, parece que EE. UU. exige a sus socios comerciales la armonización de la regulación medioambiental, posiblemente como una forma de evitar el arbitraje regulatorio y las fugas de carbono. Además, al igual que la Unión Europea, Estados Unidos también utiliza las prohibiciones de relajación de regulación medioambiental, posiblemente con el mismo objetivo. En este punto se observa un contraste en el tratamiento del derecho de los Gobiernos a regular a favor del interés público.

Finalmente, China también incluye de forma generalizada un capítulo sobre medioambiente y consagra el compromiso a una alta protección medioambiental (Cuadro 6). Sin embargo, hace un uso residual del resto de cláusulas. Por tanto, sí que estipula de forma general compromisos medioambientales, pero hasta 2015 no incluye cláusulas concretas que puedan servir para instrumentalizar dichos compromisos. $\triangleright$

CUADRO 5

ACUERDOS COMERCIALES DE ESTADOS UNIDOS

\begin{tabular}{|c|c|c|c|c|c|c|c|c|}
\hline \multirow[b]{2}{*}{$\begin{array}{l}\text { Acuerdos comerciales } \\
\text { de EE. UU. }\end{array}$} & \multirow[b]{2}{*}{$\begin{array}{l}\text { Capítulo } \\
\text { sobre } \\
\text { medioam- } \\
\text { biente }\end{array}$} & \multicolumn{3}{|c|}{ Grupo 1} & \multirow{2}{*}{$\begin{array}{c}\text { Grupo } 2 \\
\begin{array}{c}\text { Obligación } \\
\text { de } \\
\text { cooperación }\end{array}\end{array}$} & \multicolumn{3}{|c|}{ Grupo 3} \\
\hline & & $\begin{array}{c}\text { Referencia } \\
\text { general }\end{array}$ & $\begin{array}{c}\text { Alta } \\
\text { protección } \\
\text { medioam- } \\
\text { biental }\end{array}$ & $\begin{array}{c}\text { Regulación } \\
\text { medioam- } \\
\text { biental }\end{array}$ & & $\begin{array}{c}\text { Relajación } \\
\text { regulación } \\
\text { medioam- } \\
\text { biental }\end{array}$ & $\begin{array}{l}\text { Liberalización } \\
\text { sectores } \\
\text { verdes }\end{array}$ & $\begin{array}{l}\text { Evaluación } \\
\text { del impacto }\end{array}$ \\
\hline Corea - US & 1 & 1 & 1 & 1 & 0 & 1 & 0 & 0 \\
\hline US - Australia & 1 & 1 & 1 & 1 & 0 & 1 & 0 & 0 \\
\hline US - Baréin ............................. & 1 & 1 & 1 & 1 & 1 & 1 & 1 & 0 \\
\hline US - Chile .................. & 1 & 1 & 1 & 1 & 0 & 1 & 0 & 0 \\
\hline US - Colombia & 1 & 1 & 1 & 1 & 0 & 1 & 0 & 0 \\
\hline US - Israel & 0 & 0 & 1 & 0 & 0 & 0 & 0 & 0 \\
\hline US - Jordania & 1 & 1 & 1 & 1 & 0 & 0 & 0 & 0 \\
\hline US - Marruecos ............... & 1 & 1 & 1 & 1 & 0 & 1 & 0 & 0 \\
\hline US - Omán & 1 & 1 & 1 & 1 & 0 & 1 & 0 & 0 \\
\hline US - Panamá & 1 & 1 & 1 & 1 & 0 & 1 & 0 & 0 \\
\hline US - Perú & 1 & 1 & 1 & 1 & 0 & 1 & 0 & 0 \\
\hline US - Singapur ... & 1 & 1 & 1 & 1 & 0 & 1 & 0 & 0 \\
\hline Total general . & 11 & 11 & 12 & 11 & 1 & 10 & 1 & 0 \\
\hline
\end{tabular}

Fuente: elaboración propia, a partir de Content Of Deep Trade Agreements; Environmental Laws (https://datacatalog.worldbank.org/dataset/ content-deep-trade-agreements). 
CUADRO 6

ACUERDOS COMERCIALES DE CHINA

\begin{tabular}{|c|c|c|c|c|c|c|c|c|}
\hline \multirow[b]{2}{*}{$\begin{array}{l}\text { Acuerdos comerciales } \\
\text { de China }\end{array}$} & \multirow[b]{2}{*}{$\begin{array}{l}\text { Capítulo } \\
\text { sobre } \\
\text { medioam- } \\
\text { biente }\end{array}$} & \multicolumn{3}{|c|}{ Grupo 1} & \multirow{2}{*}{$\begin{array}{c}\text { Grupo } 2 \\
\begin{array}{c}\text { Obligación } \\
\text { de }\end{array} \\
\text { cooperación }\end{array}$} & \multicolumn{3}{|c|}{ Grupo 3} \\
\hline & & $\begin{array}{l}\text { Referencia } \\
\text { general }\end{array}$ & $\begin{array}{c}\text { Alta } \\
\text { protección } \\
\text { medioam- } \\
\text { biental }\end{array}$ & $\begin{array}{c}\text { Regulación } \\
\text { medioam- } \\
\text { biental }\end{array}$ & & $\begin{array}{c}\text { Relajación } \\
\text { regulación } \\
\text { medioam- } \\
\text { biental }\end{array}$ & $\begin{array}{l}\text { Liberalización } \\
\text { en sectores } \\
\text { verdes }\end{array}$ & $\begin{array}{c}\text { Evaluación } \\
\text { del } \\
\text { impacto }\end{array}$ \\
\hline APTA (China) & 0 & 0 & 0 & 0 & 0 & 0 & 0 & 0 \\
\hline ASEAN - China & 1 & 0 & 1 & 0 & 0 & 0 & 0 & 0 \\
\hline Australia - China & 0 & 0 & 0 & 0 & 0 & 0 & 0 & 0 \\
\hline Chile - China .............. & 1 & 0 & 1 & 0 & 0 & 0 & 0 & 0 \\
\hline China - Costa Rica & 1 & 0 & 0 & 0 & 0 & 0 & 0 & 0 \\
\hline China - Hong Kong & 0 & 0 & 1 & 0 & 0 & 0 & 0 & 0 \\
\hline China - Corea & 1 & 1 & 1 & 1 & 0 & 1 & 0 & 0 \\
\hline China - Macao & 0 & 0 & 1 & 0 & 0 & 0 & 0 & 0 \\
\hline China - Nueva Zelanda & 1 & 0 & 1 & 0 & 1 & 0 & 0 & 0 \\
\hline China - Singapur .... & 0 & 0 & 0 & 0 & 0 & 0 & 0 & 0 \\
\hline Islandia - China & 1 & 0 & 1 & 0 & 0 & 0 & 0 & 0 \\
\hline Pakistán - China & 1 & 0 & 0 & 0 & 0 & 0 & 0 & 0 \\
\hline Perú - China & 1 & 0 & 1 & 0 & 0 & 0 & 0 & 0 \\
\hline Suiza - China & 1 & 1 & 1 & 0 & 0 & 1 & 1 & 0 \\
\hline Total general . & 9 & 2 & 9 & 1 & 1 & 2 & 1 & 0 \\
\hline
\end{tabular}

Fuente: elaboración propia, a partir de Content Of Deep Trade Agreements; Environmental Laws (https://datacatalog.worldbank.org/dataset/content-deep-trade-agreements).

Para finalizar el análisis de las cláusulas medioambientales, es interesante estudiar la inclusión de algún mecanismo de control y supervisión. En los acuerdos comerciales, este tipo de mecanismos se instrumentaliza a partir de la existencia o no existencia de un mecanismo de solución de diferencias. El Cuadro 7 muestra un tratamiento por la UE similar al de la inclusión de evaluaciones de las cláusulas. Tradicionalmente eran cláusulas de presencia minoritaria, pero a partir de 2015 se observa un punto de inflexión, estipulando la posibilidad de acudir a un mecanismo de solución de diferencias en caso de conflicto medioambiental.

\section{Conclusiones}

Las cláusulas medioambientales se han convertido en un recurrente instrumento de la política comercial con objetivos medioambientales de la UE. Su inclusión en acuerdos comerciales regionales es el resultado de la tendencia de regionalización de las relaciones internacionales en cuestiones comerciales y medioambientales.

La protección medioambiental se puede concretar de múltiples maneras. En el ámbito comercial se traduce en que los compromisos medioambientales a los que lleguen las partes dependerán de su concreta configuración económica e intereses. Existen, pues, diversos tipos de cláusulas de sostenibilidad medioambiental, atendiendo al objetivo particular que se persiga y a la intensidad con la cual dicho compromiso es consagrado. Además, la consideración de un mecanismo de supervisión y control de su cumplimiento es un factor determinante en su efectividad.

Algunas de las principales conclusiones del análisis realizado es que la UE ha adoptado la inclusión de las cláusulas medioambientales como práctica general en la firma de acuerdos $\triangleright$ 
CUADRO 7

ACUERDOS COMERCIALES DE LA UE Y EL MECANISMO DE SOLUCIÓN DE DIFERENCIAS

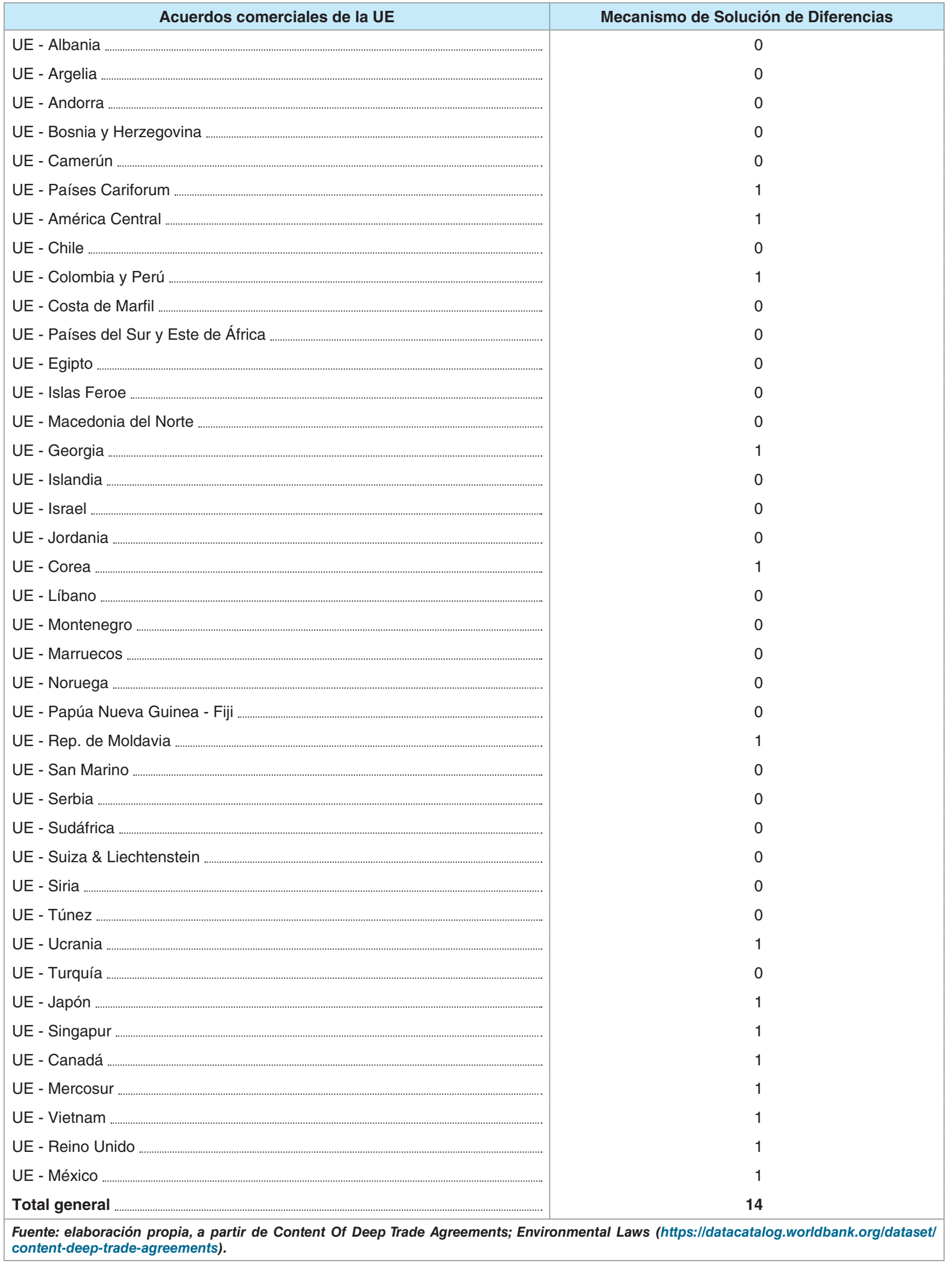


comerciales desde la década de los noventa. Su atención se centra en consagrar un alto grado de protección medioambiental y en evitar el arbitraje regulatorio en el ámbito medioambiental como forma de fomentar el comercio. Es interesante observar cómo EE. UU. sigue patrones similares, al perseguir los mismos objetivos, pero buscándolos de forma diferente, al consagrar la armonización regulatoria como forma de evitar dicho arbitraje regulatorio. Comparativamente, la Unión Europea y Estados Unidos son mucho más ambiciosos en la inclusión de cláusulas medioambientales que China.

El auge de estas cláusulas ha centrado la atención en el estudio de su efectividad y de posibles formas de mejorarla. Ejemplo de ello es la proliferación de cláusulas que consagran la obligación de realización de evaluaciones de impacto periódicas en los acuerdos de la UE, sobre todo a partir de 2015. Sentando la base para futuros trabajos, a la hora de realizar una estimación de la incidencia de las cláusulas medioambientales hay que enfrentarse a la disyuntiva entre realizar un análisis de atribución o un análisis de contribución. La primera opción es la deseable. Sin embargo, la realización de una evaluación de impacto presenta numerosas dificultades. Por un lado, existen obstáculos a la hora de construir un grupo de tratamiento y un grupo de control, al ser previsible la existencia de sesgos de selección a la hora de decidir incluir y aceptar un tipo u otro de cláusula, en función del grado de desarrollo inicial del socio comercial en cuestión. Por otro lado, existen problemas con la elección del indicador de sostenibilidad de referencia para poder realizar la evaluación, relacionados con la configuración concreta del indicador elegido y con la dificultad de contar con un indicador significativo común para la gran mayoría de acuerdos.
El presente artículo representa una contribución en esta línea, planteando el problema desde una perspectiva teórica y analizando la tipología de cláusulas existentes usadas por la UE. Todo ello para, en posteriores trabajos, poder profundizar en el efecto que tienen estas cláusulas sobre la sostenibilidad medioambiental de los socios comerciales de la UE.

\section{Bibliografía}

Buchanan, J. M. (1965). An Economic Theory of Clubs. Economica, 32(125), 1-14. https://www.jstor.org/stable/2552442

Carney, M. (29 September 2015). Breaking the trage$d y$ of the horizon-climate change and financial stability [Speech]. Lloyd's of London, Londres. https://www.bis.org/review/r151009a.pdf

Claeys, G., y Sapir, A. (2018). The European Globalisation Adjustment Fund: Easing the pain from trade? Bruegel Policy Contribution, (05).

Comisión Europea (2020). Hacia un mecanismo de la Unión de ajuste en frontera por emisiones de carbono compatible con la OMC. https://www. europarl.europa.eu/doceo/document/A-92021-0019_ES.html

Comisión Europea (2021). Comunicación (COM(2021) 66 final), de 18 de febrero de 2021, de la Comisión al Parlamento Europeo, al Consejo, al Comité Europeo Económico y Social y al Comité de las Regiones. Trade Policy Review An Open, Sustainable and Assertive Trade Policy. https://trade.ec.europa.eu/doclib/docs/2021/ february/tradoc_159438.pdf

Frankel, J. A., y Rose, A. K. (2005). Is trade good or bad for the environment? Sorting out the causality. Review of Economics and Statistics, 87(1), 85-91.https://doi.org/10.1162/0034653053327577

Green, A., y Epps, T. (2009). Is there a role for trade measures in addressing climate change. UC Davis Journal of International Law \& Policy, 15, 1. $\triangleright$ 
Martínez-Zarzoso, I. (2018). Assessing the Effectiveness of Environmental Provisions in Regional Trade Agreements: An Empirical Analysis (Working Papers No. 2018/02) OECD Environment and Trade. https://dx.doi.org/10.1787/5ffc615c-en

Martínez-Zarzoso I. y Chelala, S. (2021). Trade agreements and international technology transfer. Review of World Economics, (157), 631-665. https://doi.org/10.1007/s10290-021-00420-7

Nordhaus, W. D. (1974). Resources as a Constraint on Growth. The American Economic Review, 64(2), 22-26.

Nordhaus, W. (2015). Climate Clubs: Overcoming Free-riding in International Climate Policy. American Economic Review, 105(4), 1339-1370. http:// dx.doi.org/10.1257/aer.15000001

Olson, M. (1971). The Logic of Collective Action: Public Goods and the Theory of Groups. Harvard economic studies, 124. Harvard University Press.
Parlamento Europeo (2018). European Parliament resolution of 13 March 2018 on gender equality in EU trade agreements. https://www.europarl. europa.eu/doceo/document/TA-8-2018-0066 EN.html

Parlamento Europeo (2020). Hacia un mecanismo de la Unión de ajuste en frontera por emisiones de carbono compatible con la OMC. https:// www.europarl.europa.eu/doceo/document/A-92021-0019_ES.html

Quinn, J., y Trebilcock, M. J. (1982). Compensation, Transition and Regulatory Change. The University of Toronto Law Journal, 32(2), 117-175. https:// doi.org/10.2307/825521

Van Asselt, H. (2017). Climate change and trade policy interaction: Implications of regionalism (OECD Trade and Environment Working Papers). https://dx.doi.org/10.1787/c1bb521e-en 
